\title{
Challenges and opportunities of transgenic agricultural products in Iran: convergence of perspectives using Delphi technique
}

\author{
Fatemeh Badghan, Razieh Namdar * (1) and Naser Valizadeh (1)
}

\begin{abstract}
Background: Widespread production and use of transgenic products across the world in recent decade has led to different reactions and point of views. Iran is also one of the consumers of these products. However, there has been an ever-increasing controversy between supporters and opponents of the use of these products in Iran and no constructive agreement has been attained on this issue. Accordingly, the main goal of present study was to determine the challenges and opportunities of transgenic agricultural products in biotechnology and plant breeding specialists' point of view.

Methodology: Delphi technique was used to achieve this goal. The statistical population was Iranian specialists in plant breeding, biotechnology, and genetic modification. The snowball sampling approach was employed to select the samples.

Results: In general, 16 concepts in the dimension of opportunities and 25 concepts in the dimension of the challenges were identified. Analyzing the agreement rates showed that the panel of experts agree most on 14 concepts out of 16 concepts identified for opportunities. In the dimension of challenges for transgenic products, only 17 concepts received acceptable agreement scores (over 80\%).

Conclusion: In general, categorizing the concepts of transgenic products' opportunities led to identification of two main aspects namely "food security" and "biosafety". Challenges were also categorized into four strata of structural, educational, cognitive, and informational challenges. In addition, it should be mentioned that the lack of familiarity with methods, goals, and results of genetic engineering and gene transferring methods in transgenic plants is the most important aspect of people's concern. Although it is not possible to get full knowledge about genetic engineering and genetic manipulation methods for all those who are the consumers of transgenic products, their awareness and recognition about the goals and positive/negative effects of the use of these products can be increased using specific strategies. For instance, one of the strategies is to focus and invest on mass media that which provides high availability, vast coverage, and low-cost. Accordingly, mass media (such as radio and television) can act as the best educational and informational tools for development and application of transgenic plants.
\end{abstract}

Keywords: Delphi technique, Genetic engineering, Agricultural products, Specialists

*Correspondence: r.namdar@shirazu.ac.ir

Department of Agricultural Extension and Education, School

of Agriculture, Shiraz University, Shiraz 7144165186, Iran

\section{Background}

Plants are one of the main sources of food for humankind and are at the head of the food pyramid. Cereals and beans are the most important herbal products that are considered as the main food sources for humans [1]. In addition, agricultural products have played a significant

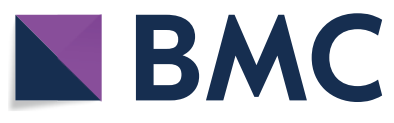

(c) The Author(s) 2020. This article is licensed under a Creative Commons Attribution 4.0 International License, which permits use, sharing, adaptation, distribution and reproduction in any medium or format, as long as you give appropriate credit to the original author(s) and the source, provide a link to the Creative Commons licence, and indicate if changes were made. The images or other third party material in this article are included in the article's Creative Commons licence, unless indicated otherwise in a credit line to the material. If material is not included in the article's Creative Commons licence and your intended use is not permitted by statutory regulation or exceeds the permitted use, you will need to obtain permission directly from the copyright holder. To view a copy of this licence, visit http://creativeco mmons.org/licenses/by/4.0/. The Creative Commons Public Domain Dedication waiver (http://creativecommons.org/publicdomain/ zero/1.0/) applies to the data made available in this article, unless otherwise stated in a credit line to the data. 
role in development of human civilization. In other words, human civilization and agricultural advances have taken place in parallel $[2,3]$.

During thousands of years, human beings have modified and improved crops through trial and error and repeated cycles of selection. The interesting thing is that they were quite successful in doing that [3]. They modified the plant genes to develop products that are rich in terms of fiber, feed, and energy [2].

Without a doubt, the rapid population growth and increased demand for more and better food will exacerbate social, political, and economic threats and endanger environmental sustainability in the near future $[4,5]$. It is expected that by 2050, the world's population will reach 9.7 billion and demand for food production and distribution will increase by 59-98\% [6]. Despite all efforts to provide food for current population of the world, estimates show that 820 million people were suffering from undernourishment in 2018 and it is estimated that this count will reach to about 840 million in the near future. Measures show that 255.5 million people in Africa, 1.515 million people in Asia, and 39.3 million in Latin America and the Caribbean are suffering from undernourishment. It should also be noted that the majority of people who suffer from undernourishment are in underdeveloped or developing countries. Nevertheless, the surveys reveal that $2.5 \%$ of people in developed countries also suffer from undernourishment [7].

In addition to increasing trend of population growth and hunger in the world, scarcity of mineral and trace elements (especially vitamin A, iodine, and iron), evolution of the global climate patterns, political instabilities, changes in land use patterns, and regional production problems will also exacerbate the demand for food and will threaten the food security [8-10]. Alongside these challenges in production, there is an increasing interest in functional foods that have healthier characteristics beyond basic nutrition [6].

Given these challenges, a new solution must be provided to meet the basic needs of the world's population in next few decades. Although it may not be possible to solve the above-mentioned challenges only using one specific technological advance, but critical assessment of the role of new technologies as a solution to these crises is of great importance [6]. Biotechnology has been described as one of the greatest technologies and developments in present century and it is also considered as the "New Green Revolution" that can contribute to eradication of poverty and hunger $[6,11]$. At present, the green revolution has emerged as a "gene revolution" and has led to production of genetically modified organisms $[3,12]$.
Nowadays, production of transgenic plants is considered as a new approach to achieve food security and sustainable development [13] and employment of genetic modification technology in agri-food sector is one of the most common applications of this technology. These products have been grown rapidly and steadily throughout the world over the last two decades. In 2013, 18 million farmers in 27 countries cultivated 175.2 million hectares of transgenic crops. This covered area has experienced a $3 \%$ increase (5 million hectares) in comparison with 2012 [14]. According to International Service for Acquisition of Agri-Biotech Applications (ISAAA) in 2018, GM crops covered over 191.7 million hectares of agricultural lands. These figures show the importance of transgenic products in terms of supply [15].

The direct link between transgenic products and food security has been a major factor in their significant development $[16,17]$. It can be said that there are three possible pathways that explain how GM crops could impact food security [18]. First, GM crops could contribute to food production increases and thus improve the availability of food at global and local levels [19]. GM technologies could make food crops higher yielding and more robust to biotic and abiotic stresses. This could stabilize and increase food supplies, which is important in confronting with the increasing food demand, climate change, and land and water scarcity [18]. Second, GM crops could affect food safety and food quality. Concerning the second pathway, crops with new traits can be associated with food safety risks, which have to be assessed and managed case by case [20]. But such risks are not specific to GM crops. Long-term research confirms that GM technology is not per se more risky than conventional plant breeding technologies. On the other hand, GM technology can help to breed food crops with higher contents of micronutrients. A case in point is Golden Rice with provitamin A in the grain. Such GM crops have not yet been commercialized. Projections show that they could reduce nutritional deficiencies among the poor, entailing sizeable positive health effects $[18,19]$. Third, GM crops could influence the economic and social situation of farmers, thus improving or worsening their economic access to food. This latter aspect is of particular importance given that an estimated 50\% of all undernourished people worldwide are small-scale farmers in developing countries. The third pathway relates to GM crop use by smallholder farmers in developing countries. Studies have shown that benefits associated with GM crop leads to increases in farm household income and living standard. Higher incomes are generally expected to cause increases in food consumption in poor farm households [18]. 
With the growing trend of cultivating transgenic agricultural products in different parts of the world, a variety of opportunities and challenges have emerged regarding introduction of transgenic technology to the people. As one of the major users of transgenic products, Iran is no exception; and so the use and promotion of planting these products have been accompanied by various comments in recent years. Proponents of production of genetically modified organisms believe that Iran will have to use these products to meet the growing needs of its population $[13,17]$. In other words, while food security is endangered by "low performance of agricultural products" and "political and economic sanctions", transgenic agricultural products provide an opportunity to stabilize and provide the food needed by deprived social groups [17]. In addition, many supporters of transgenic products put emphasize on the other benefits of these products including their independence to farm size, increased farm income [21, 22], having more attractiveness for farmers [22], reusing of salt-affected lands, overcoming the energy crisis [3], producing cost-effective biopharmaceuticals, increasing plant resistance to tensions and pests $[13,23]$, reducing labor costs and use of pesticides/ herbicides/fertilizers [3], producing new types of products with useful features [17, 24], reducing deforestation and enhancing biodiversity conservation $[18,25]$ and reducing food wastes and costs [24].

However, transgenic agricultural products' opponents believe that in some cases such advanced technologies are inappropriate for small-scale farmers and disturb traditional farming systems. Also, critics emphasize that the dominance of multinational companies in the field of biotechnology and the development of Intellectual Property Rights (IPRs) at international level will lead to the exploitation of agricultural producers. In this point of view, transgenic products are considered as a threat to food security and food production [18]. Other criticisms of the use of transgenic products in Iran are including illegal production and distribution of unauthorized seeds and collapse of traditional agriculture [11], regulation and market [21], reducing the number of small farmers, economic losses of small farmers [26], elimination of purity of foods [4], depending farmers on specific inputs, food foreclosures [17], biological colonization, neglecting consumer rights [26], failure to control the transfer of genes to wild plants, increasing resistance to herbicides, insects, and viruses in wild ancestors, reducing genetic reserves and harmful effects on beneficial organisms [26].

Despite all this criticism of transgenic products, it is worth mentioning that the recent international OECD risk assessment methodology ensures gene flow, resistance, and other scientific issues have been reviewed by experts in the over 70 countries which produce and import GM crops. No issues of concern have been identified [27]. Some international evidences can be found in the literature about the benefits of well-known GM crops. Pray et al. [28] have investigated the benefits of GM cotton in India or China. The results of this study revealed that increases in yields, major reductions in pesticide use and increased profits for farmers adopting GM cotton are among the most important perks of GM cotton in China. In addition, GM cotton adoption led to reduced pesticide use, which resulted in farmers reporting fewer pesticide-related- illnesses. In India, results of GM adoption were different. Introduction of insect resistance had a significant impact on yields, with increases of 40 to $80 \%$, as farmers in India did not have access to a good and available pest control. Reduction in pesticide use for bollworm control was also substantial, but less than in China. Like Chinese farmers, Indian farmers increased their net incomes despite higher seed prices.

As stated above, there is no agreement among the supporters and opponents of the use of transgenic agricultural products in Iran. In addition, due to the fact that some of imported transgenic products do not meet the required national standards, the government has also tried to limit the production and use of these products by passing laws and bills. However, it is clear that prohibition of the production and use of transgenic products require precise mechanisms in social, economic, and cultural spheres in order to be able to substitute the gaps emerged in needed products. On the other hand, many of these disagreements are generally due to the lack of negotiation and cooperation between proponents and opponents of the use of transgenic products. So they cannot convince each other with scientific evidences and come to a constructive and common agreement. In this regard, the main objective of this study was to analyze the challenges and opportunities of transgenic products in Iran using Delphi method. This general objective was achieved through four specific objectives:

- Analysis of specialists' opinions about the opportunities of transgenic agricultural products;

- Analysis of specialists' opinions about the challenges of transgenic agricultural products;

- Assessment of the level of agreement on the challenges and opportunities of transgenic agricultural products; and

- Categorization and prioritization of opportunities and challenges for transgenic agricultural products.

\section{Materials and methods}

Present study is an applied and qualitative-quantitative research that was conducted using Delphi technique. Statistical population consisted of experts (specialists) of 
plant breeding, biotechnology, and Agriculture and Natural Resources Research and Education Centers in Iran, from whom 30 specialists were selected as samples using snowball sampling approach. In the first step of implementing snowball sampling method, two experts (supporter and opponent of transgenic products) who had a large scientific and practical experience in this field were selected as the first samples. In the second phase, the first step participants were asked to introduce the third and fourth specialists in the field of transgenic products. A similar process was used to select the next samples. Finally, data were collected from 30 participants. Sample selection continued until reaching to theoretical saturation. Due to the facts that in the analysis of findings gathered from final samples it became clear that selection of more samples will not lead to more information related to the research questions, the sampling process was ended. In fact, there is no strong and explicit rule for the number of specialists (samples) in Delphi panel. In other words, the sample size in Delphi method depends on achievement to theoretical saturation, homogeneity or heterogeneity of the samples, Delphi goal, breadth of the problem, quality of decision, ability of the research team to conduct the study, data collection time, and so on [29]. As a result, in Delphi technique the size of sample and its randomness does not matter [30].

The reason for using Delphi technique was that the issue of transgenic products is a complex argument in which there is no general agreement and acceptable framework. Complexity, disagreement, and absence of a predetermined framework are the basics of using Delphi technique [31]. It involves a group of individuals into a complex issue/problem. Model construction in this technique takes place during research process and through classification of data [31]. Application of this method usually requires conducting several interdependent rounds. Although there is little agreement on the number of rounds in Delphi technique and it may vary from 2 to 10 rounds in different studies [30,31], but in this study a five-round process was employed.

In the first step, the research problem was defined by research team and the characteristics of participants in Delphi panel were determined using the nature of the problems within the study. Then, the panel of participations were identified (using snowball sampling) and invited to complete the questionnaire. This step was completed by appointing panel members.

In the second step, a questionnaire was designed which included four sections. The first section included a complete introduction of subject and purpose of the research. The second section was consisted of some questions about participants' general information, like field of study, level of education, gender, and age.
The third and fourth sections encompassed two openended questions about the opportunities and challenges of agricultural transgenic products. At the end of the second step, a list of concepts about opportunities and challenges of transgenic products was extracted (see Table 1) which paved the way for implementing third step.

In the third step, the concepts extracted from the second step were configured in the form of a close-ended questionnaire. The purpose of this work was to examine the extent to which experts agreed with each concept. Therefore, the concepts converted into questions with five-point Likert-type scale (1: totally disagree to 5 : totally agree). There were two main parts in this questionnaire, the first part included an introduction about research goal and a guide for how to respond to questions. In this part of questionnaire, we provided some more information for respondents as well. For example, participants were informed that the items introduced in this questionnaire are not merely including the concepts extracted from their own views (as a supporter or opponent of transgenic products) and it does contain concepts provided by all panel members. In fact, the respondents got familiar with the views of other experts and specified their degree of agreement on each of the cases. The second part of questionnaire consisted of concepts related to opportunities and challenges in the form of five-point Likert scale. The questionnaires were given to the experts (30 participants of the first step) and all members of the panel presented their views. After receiving responses, results were entered into SPSS $_{22}$ software and the concepts ranked using mean and standard deviation (Table 2).

The fourth step was carried out to reach an agreement. In this regard, another questionnaire was designed to examine the degree of consensus on the challenges and opportunities of transgenic products. To this end, the concepts used in third round (step) were configured in the form of two-choice questions $(1=$ agree and $2=$ disagree). Similar to previous steps, the first part of the questionnaire included introduction and a guide for response. The second part of the questionnaire included concepts used in the third round. At this step, five-point Likert scale was replaced with two-choice questions (Table 3). It should be mentioned that the specific score of each participant and the average score of all participants to a particular concept in the previous step were given to the respondents. Because in this case they could see the differences between their own responses and the other experts, such information allowed the respondents to change or revise their views on each of the challenges and 


\section{Table 1 Raw list of the opportunities and challenges extracted for transgenic products}

\begin{tabular}{ll}
\hline Row & Extracted concepts for opportunities \\
\hline 1 & Like natural herbs, transgenic plants completely decompose and return to nature \\
3 & Increasing growth of transgenic plants around the world is an indicator of their acceptance by farmers \\
4 & Having natural and beneficial genes is the main distinction between transgenic plants and other plants \\
5 & The technology of transgenic plants supports sustainable agriculture development goals \\
6 & Transgenic foods are healthy and like ordinary foods are considered safe to eat \\
7 & Transgenic plants reduce the use of pesticides and thus contribute to protection of environment \\
8 & Cultivation of transgenic plants preserves biodiversity \\
9 & Production of transgenic plants boosts resistance to pests and diseases \\
10 & Transgenic plants help control weeds \\
11 & Cultivation of transgenic plants minimizes pesticide residues in food products and environment \\
12 & Cultivation of transgenic plants can lead to soil protection \\
13 & Transgenic plants reduce the negative environmental impacts of agricultural activities \\
14 & Population growth and nutritional needs of human beings reflect the necessity of producing transgenic plants \\
15 & Transgenic technology is in progress and provides new opportunities for agricultural production \\
16 & Increasing agricultural production, boosting economic profits, and eliminating poverty are among the benefits of transgenic plants \\
\hline
\end{tabular}

Row Extracted concepts for challenges

1 There is no consensus among experts on the usage of transgenic products

2 Lack of consensus on potential risks of transgenic plants has prevented the massive production of these products

3 Resistance of consumers has prevented the spread of transgenic plants in some countries (including Iran)

$4 \quad$ Resistance of politicians in some countries (like Iran) has limited the spread of transgenic plants

5 Production of transgenic plants in Iran is unnecessary and traditional breeding methods can meet future food needs

6 Lack of an educational, research, and development System (ERDS) is a significant barrier for development of this new technology

$7 \quad$ Production of transgenic plants destroys valuable resources and resists pests

$8 \quad$ Transgenic plants produce damage to other species (non-target species)

9 Lack of an enabling environment for private sectors' activity has led to slow growth and development of transgenic products in agricultural sector

10 Lack of awareness of consumers and manufacturers about the features of transgenic technology is an obstacle for its development

11 Lack of educators and knowledgeable specialists in development of transgenic plants is one of the main challenges in this area

12 The use of transgenic plants can create risks for human reproduction and fertility

13 The use of transgenic plants may lead to resistance to antibiotics

14 The use of transgenic plants may cause tumors (cancer) and allergies in individuals

15 Managerial systems, regulatory agencies, and controllers of transgenic plant production are faced with major problems in Iran

16 The process of generating knowledge and technology on transgenic plants is very slow in Iran

17 Little attention of authorities to production of transgenic plants reduces the rate of productivity and increases the need for resources of energy

18 Lack of familiarity with methods, goals, and results of genetic engineering causes people to be concerned about the acceptance of transgenic plants

19 Due to the political issues and deficiencies in planning, the production of transgenic plants has faced with some problems

20 The risky dimensions of transgenic plants are certainly not proven and these negative impacts should not be ignored

21 Administrative bureaucracy is one of the main problems of transgenic plants' development

22 Inconspicuous role of the mass media in introducing the achievements of transgenic technology has led to backwardness of this technology

23 Lack of accurate statistical information on transgenic plants has prevented the growth of this area

24 The country's inappropriate customs rules are of main barriers for development of this new technology

25 Non-certification of the use of transgenic products by recognized scientific and research authorities is one of the weaknesses in their application

opportunities if they wished. In the final step, the results were categorized as more general factors in order to further clarification of the challenges and opportunities (Table 4). 
Table 2 Rankings of the concepts related to the opportunities and challenges of transgenic products (number respondents $=30$ )

\begin{tabular}{|c|c|c|c|}
\hline Rank & The concepts of opportunities & Mean & $\begin{array}{l}\text { Standard } \\
\text { deviation }\end{array}$ \\
\hline 1 & Population growth and nutritional needs of human beings reflect the necessity of producing transgenic plants & 4.55 & 0.57 \\
\hline 2 & The technology of transgenic plants supports sustainable agriculture development goals & 4.53 & 0.73 \\
\hline 3 & Like natural herbs, transgenic plants completely decompose and return to nature & 4.53 & 0.90 \\
\hline 4 & Transgenic technology is in progress and provides new opportunities for agricultural production & 4.50 & 0.68 \\
\hline 5 & Transgenic plants reduce the use of pesticides and thus contribute to protection of environment & 4.37 & 0.90 \\
\hline 6 & Cultivation of transgenic plants minimizes pesticide residues in food products and environment & 4.28 & 0.88 \\
\hline 7 & $\begin{array}{l}\text { Increasing agricultural production, boosting economic profits, and eliminating poverty are among the benefits of trans- } \\
\text { genic plants }\end{array}$ & 4.27 & 0.94 \\
\hline 8 & Transgenic products have higher nutritional value than other plants & 4.26 & 0.94 \\
\hline 9 & Production of transgenic plants boosts resistance to pests and diseases & 4.17 & 0.91 \\
\hline 10 & Transgenic plants reduce the negative environmental impacts of agricultural activities & 4.13 & 0.86 \\
\hline 11 & Transgenic foods are healthy and like ordinary foods are considered safe to eat & 4.13 & 1.04 \\
\hline 12 & Transgenic plants help control weeds & 4.03 & 0.77 \\
\hline 13 & Having natural and beneficial genes is the main distinction between transgenic plants and other plants & 4.00 & 0.78 \\
\hline 14 & Cultivation of transgenic plants can lead to soil protection & 4.00 & 0.92 \\
\hline 15 & Cultivation of transgenic plants preserves biodiversity & 3.83 & 1.053 \\
\hline 16 & Increasing growth of transgenic plants around the world is an indicator of their acceptance by farmers & 3.83 & 1.289 \\
\hline Rank & The concepts of challenges & Mean & $\begin{array}{l}\text { Standard } \\
\text { deviation }\end{array}$ \\
\hline 1 & Due to political issues and deficiencies in planning, the production of transgenic plants has faced with some problems & 4.40 & 0.72 \\
\hline 2 & Resistance of politicians in some countries (like Iran) has limited the spread of transgenic plants & 4.37 & 0.99 \\
\hline 3 & $\begin{array}{l}\text { Lack of familiarity with methods, goals, and results of genetic engineering causes people to be concerned about the } \\
\text { acceptance of transgenic plants }\end{array}$ & 4.33 & 0.95 \\
\hline 4 & Production of transgenic plants in Iran is unnecessary and traditional breeding methods can meet future food needs & 4.27 & 1.08 \\
\hline 5 & $\begin{array}{l}\text { Inconspicuous role of the mass media in introducing the achievements of transgenic technology has led to backwardness } \\
\text { of this technology }\end{array}$ & 4.13 & 0.90 \\
\hline 6 & $\begin{array}{l}\text { Managerial systems, regulatory agencies, and controllers of transgenic plant production are faced with major problems in } \\
\text { Iran }\end{array}$ & 4.13 & 1.13 \\
\hline 7 & $\begin{array}{l}\text { Little attention of authorities to production of transgenic plants reduces the rate of productivity and increases the need for } \\
\text { resources of energy }\end{array}$ & 3.97 & 0.89 \\
\hline 8 & $\begin{array}{l}\text { Lack of an educational, research, and development (ERD) system is a significant barrier for development of this new } \\
\text { technology }\end{array}$ & 3.93 & 1.01 \\
\hline 9 & $\begin{array}{l}\text { Lack of educators and knowledgeable specialists in development of transgenic plants is one of the main challenges in this } \\
\text { area }\end{array}$ & 3.86 & 1.10 \\
\hline 10 & $\begin{array}{l}\text { Lack of awareness of consumers and manufacturers about the features of transgenic technology is an obstacle for its } \\
\text { development }\end{array}$ & 3.86 & 1.38 \\
\hline 11 & Administrative bureaucracy is one of the main problems of transgenic plants' development & 3.83 & 0.88 \\
\hline 12 & $\begin{array}{l}\text { Lack of an enabling environment for private sector's activity has led to slow growth and development of transgenic prod- } \\
\text { ucts in agricultural sector }\end{array}$ & 3.83 & 1.02 \\
\hline 13 & The process of generating knowledge and technology on transgenic plants in Iran is very slow & 3.63 & 1.18 \\
\hline 14 & The risky dimensions of transgenic plants are certainly not proven and these negative impacts should not be ignored & 3.63 & 1.29 \\
\hline 15 & Lack of consensus on potential risks of transgenic plants has prevented the massive production of these products & 3.63 & 1.32 \\
\hline 16 & Lack of accurate statistical information on transgenic plants has prevented the growth of this area & 3.57 & 1.10 \\
\hline 17 & The country's inappropriate customs rules are of main barriers for development of this new technology & 3.40 & 1.19 \\
\hline 18 & There is no consensus among experts on the usage of transgenic products & 3.37 & 1.49 \\
\hline 19 & $\begin{array}{l}\text { Non-certification of the use of transgenic products by recognized scientific and research authorities is one of the weak- } \\
\text { nesses in their application }\end{array}$ & 3.30 & 1.46 \\
\hline 20 & Resistance of consumers has prevented the spread of transgenic plants in some countries (including Iran) & 2.97 & 1.35 \\
\hline 21 & Transgenic plants produce damage to other species (non-target species) & 2.40 & 1.32 \\
\hline 22 & Production of transgenic plants destroys valuable resources and resists pests & 2.23 & 1.22 \\
\hline
\end{tabular}


Table 2 (continued)

\begin{tabular}{|c|c|c|c|}
\hline Rank & The concepts of challenges & Mean & $\begin{array}{l}\text { Standard } \\
\text { deviation }\end{array}$ \\
\hline 23 & The use of transgenic plants may lead to resistance to antibiotics. & 2.17 & 1.26 \\
\hline 24 & The use of transgenic plants may cause tumors (cancer) and allergies in individuals & 2.07 & 1.23 \\
\hline 25 & The use of transgenic plants can create risks for human reproduction and fertility & 2.06 & 1.16 \\
\hline
\end{tabular}

\section{Results and discussion}

The first round included the appointment of a panel of experts to participate in the study. Therefore, a questionnaire was designed by authors and sent to the respondents. By analyzing the results of the second round, a set of concepts was extracted that respondents believed could be considered as the major challenges and opportunities of agricultural transgenic products. In summary, 16 concepts for opportunities of transgenic products and 25 concepts for challenges of transgenic products were extracted. The full list of these concepts is shown in Table 1.

In the third step, experts' opinions on the opportunities and challenges of agricultural products were questioned in the form of a five-point scale. The purpose of this process was to examine the extent to which experts agreed with each of the concepts. The results of this step are presented in Table 2. In this table, concepts having higher average score ranked better than other concepts. In the case of equivalence of concepts' mean, standard deviation was used as a benchmark for ranking. In other words, the concept with a lower standard deviation obtained higher rank.

The results of rankings showed that out of 16 concepts introduced as the opportunities, the means of 14 concepts were higher than 4 , indicating the agreement of panel on these issues. In this dimension, two concepts "population growth and nutritional needs of human beings reflect the necessity of producing transgenic plants" and "the technology of transgenic plants supports sustainable agriculture development goals" with the means of $4.55(\mathrm{SD}=0.57)$ and $4.53(\mathrm{SD}=0.73)$, respectively, ranked the highest. On the other hand, two concepts "cultivation of transgenic plants preserves biodiversity" and "increasing growth of transgenic plants around the world is an indicator of their acceptance by farmers" with the means of $3.83(\mathrm{SD}=1.053)$ and 3.83 $(\mathrm{SD}=1.289)$, respectively, ranked the lowest.

The results of rankings also showed that out of 25 concepts introduced as the challenges, the means of 6 concepts were higher than 4 , indicating the agreement of panel on these issues. In challenges dimension, two concepts "due to political issues and deficiencies in planning, the production of transgenic plants has faced with some problems" and "resistance of politicians in some countries (like Iran) has limited the spread of transgenic plants" with the means of $4.40(\mathrm{SD}=0.72)$ and 4.37 ( $\mathrm{SD}=0.99)$, respectively, ranked the highest. On the other hand, two concepts "the use of transgenic plants may cause tumors (cancer) and allergies in individuals" and "the use of transgenic plants can create risks for human reproduction and fertility" with the means of 2.07 $(\mathrm{SD}=1.23)$ and $2.06(\mathrm{SD}=1.16)$, respectively, ranked the lowest.

In the fourth step, the level agreement on the challenges and opportunities of transgenic products was examined (Table 3). To this end, experts were asked to specify the extent to which they would agree with the concepts outlined in previous step. This step was designed to reach an agreement. To this end, the concepts used in third round (step) were configured in the form of two-choice questions $(1=$ agree and $2=$ disagree $)$. At this step, fivepoint Likert scale was replaced with two-choice questions (Table 3). The main difference of this step (Table 3) and previous (third) step (Table 2) is that in the third step the participants were asked to specify the "level of agreement" on each concept. However, in the fourth step they were asked to state their definitive position on each concept. In other words, they had to determine whether they agreed or disagreed (two-choice questions) with each concept. The specific score of each respondent and the average score of all respondents to a specific concept (obtained in the third step) were given to the respondents in fourth step. Because in this case they could see the difference between their own responses and responses of other experts, such information allowed the participants to change or revise their views on each of the challenges and opportunities if they wished. The difference in the importance of the concepts presented in Tables 2 and 3 stems from this fact. Because in the fourth step, the experts of transgenic products had to give their definite opinion about each item according to the level of agreement of the rest of the panel members about that item (which was obtained in the third step), this is a technique that Delphi method uses to converge the perspectives of panel members. In other words, the differences in the results of Tables 2 and 3 show how panel members (proponents and opponents) have changed their perspectives 


\section{Table 3 Percentage of agreement on the opportunities and challenges of transgenic products (number} respondents $=30$ )

\begin{tabular}{|c|c|}
\hline Rank & The concepts of opportunities \\
\hline 1 & Population growth and nutritional needs of human beings reflect the necessity of producing transgenic plants \\
\hline 2 & The technology of transgenic plants supports sustainable agriculture development goals \\
\hline 3 & Like natural herbs, transgenic plants completely decompose and return to nature \\
\hline 4 & Transgenic technology is in progress and provides new opportunities for agricultural production \\
\hline 5 & Transgenic plants reduce the use of pesticides and thus contribute to protection of environment \\
\hline 6 & Having natural and beneficial genes is the main distinction between transgenic plants and other plants \\
\hline 7 & Increasing agricultural production, boosting economic profits, and eliminating poverty are among the benefits of transgenic plants \\
\hline 8 & Production of transgenic plants boosts resistance to pests and diseases \\
\hline 9 & Transgenic plants reduce the negative environmental impacts of agricultural activities \\
\hline 10 & Cultivation of transgenic plants minimizes pesticide residues in food products and environment \\
\hline 11 & Transgenic foods are healthy and like ordinary foods are considered safe to eat \\
\hline 12 & Transgenic plants help control weeds \\
\hline 13 & Transgenic products have higher nutritional value than other plants \\
\hline 14 & Cultivation of transgenic plants can lead to soil protection \\
\hline 15 & Cultivation of transgenic plants preserves biodiversity \\
\hline 16 & Increasing growth of transgenic plants around the world is an indicator of their acceptance by farmers \\
\hline
\end{tabular}

Rank The concepts of challenges

Production of transgenic plants in Iran is unnecessary and traditional breeding methods can meet future food needs

Due to political issues and deficiencies in planning, the production of transgenic plants has faced with some problems

Lack of familiarity with methods, goals, and results of genetic engineering causes people to be concerned about the acceptance of transgenic plants

$4 \quad$ Inconspicuous role of the mass media in introducing the achievements of transgenic technology has led to backwardness of this technology

$5 \quad$ Little attention of authorities to production of transgenic plants reduces the rate of productivity and increases the need for resources of energy

Lack of an educational, research, and development (ERD) system is a significant barrier for development of this new technology

Lack of awareness of consumers and manufacturers about the features of transgenic technology is an obstacle for its development

8 Lack of educators and knowledgeable specialists in development of transgenic plants is one of the main challenges in this area

9 Lack of an enabling environment for private sector's activity has led to slow growth and development of transgenic products in agricultural sector

10 Lack of accurate statistical information on transgenic plants has prevented the growth of this area

Non-certification of the use of transgenic products by recognized scientific and research authorities is one of the weaknesses in their application

12 There is no consensus among experts on the usage of transgenic products

Managerial systems, regulatory agencies, and controllers of transgenic plant production are faced with major problems in Iran Resistance of politicians in some countries (like Iran) has limited the spread of transgenic plants

Lack of consensus on potential risks of transgenic plants has prevented the massive production of these products

Administrative bureaucracy is one of the main problems of transgenic plants' development

The process of generating knowledge and technology on transgenic plants in Iran is very slow

The risky dimensions of transgenic plants are certainly not proven and these negative impacts should not be ignored

The country's inappropriate customs rules are of main barriers for development of this new technology

Resistance of consumers has prevented the spread of transgenic plants in some countries (including Iran)

Transgenic plants produce damage to other species (non-target species)

The use of transgenic plants may lead to resistance to antibiotics

Production of transgenic plants destroys valuable resources and resists pests

The use of transgenic plants can create risks for human reproduction and fertility

The use of transgenic plants may cause tumors (cancer) and allergies in individuals
Percentage

agreement

(6)


Table 4 Categorization of the opportunities and challenges of agricultural transgenic products

\begin{tabular}{|c|c|}
\hline Opportunities & Concepts \\
\hline \multirow{5}{*}{$\begin{array}{l}\text { Food security (availabil- } \\
\text { ity, quality, and safety) }\end{array}$} & Population growth and nutritional needs of human beings reflect the necessity of producing transgenic plants \\
\hline & Transgenic technology is in progress and provides new opportunities for agricultural production \\
\hline & $\begin{array}{l}\text { Increasing agricultural production, boosting economic profits, and eliminating poverty are among the benefits of transgenic } \\
\text { plants }\end{array}$ \\
\hline & Transgenic foods are healthy and like ordinary foods are considered safe to eat \\
\hline & Transgenic products have higher nutritional value than other plants \\
\hline \multirow[t]{9}{*}{ Biosafety } & The technology of transgenic plants supports sustainable agriculture development goals \\
\hline & Like natural herbs, transgenic plants completely decompose and return to nature \\
\hline & Transgenic plants reduce the use of pesticides and thus contribute to protection of environment \\
\hline & Having natural and beneficial genes is the main distinction between transgenic plants and other plants \\
\hline & Production of transgenic plants boosts resistance to pests and diseases \\
\hline & Transgenic plants reduce the negative environmental impacts of agricultural activities \\
\hline & Cultivation of transgenic plants minimizes pesticide residues in food products and environment \\
\hline & Transgenic plants help control weeds \\
\hline & Cultivation of transgenic plants can lead to soil protection \\
\hline Challenges & Concepts \\
\hline \multirow{7}{*}{ Structural-managerial } & Production of transgenic plants in Iran is unnecessary and traditional breeding methods can meet future food needs \\
\hline & Due to political issues and deficiencies in planning, the production of transgenic plants has faced with some problems \\
\hline & $\begin{array}{l}\text { Little attention of authorities to production of transgenic plants reduces the rate of productivity and increases the need for } \\
\text { resources of energy }\end{array}$ \\
\hline & $\begin{array}{l}\text { Lack of an enabling environment for private sector's activity has led to slow growth and development of transgenic products } \\
\text { in agricultural sector }\end{array}$ \\
\hline & Managerial systems, regulatory agencies, and controllers of transgenic plant production are faced with major problems in Iran \\
\hline & Resistance of politicians in some countries (like Iran) has limited the spread of transgenic plants \\
\hline & Administrative bureaucracy is one of the main problems of transgenic plants' development \\
\hline \multirow[t]{6}{*}{ Educational } & $\begin{array}{l}\text { Lack of an educational, research, and development (ERD) system is a significant barrier for development of this new technol- } \\
\text { ogy }\end{array}$ \\
\hline & Lack of educators and knowledgeable specialists in development of transgenic plants is one of the main challenges in this area \\
\hline & $\begin{array}{l}\text { Non-certification of the use of transgenic products by recognized scientific and research authorities is one of the weaknesses } \\
\text { in their application }\end{array}$ \\
\hline & There is no consensus among experts on the usage of transgenic products \\
\hline & Lack of consensus on potential risks of transgenic plants has prevented the massive production of these products \\
\hline & The process of generating knowledge and technology on transgenic plants in Iran is very slow \\
\hline \multirow[t]{2}{*}{ Cognitive } & $\begin{array}{l}\text { Lack of familiarity with methods, goals, and results of genetic engineering causes people to be concerned about the accept- } \\
\text { ance of transgenic plants }\end{array}$ \\
\hline & $\begin{array}{l}\text { Lack of awareness of consumers and manufacturers about the features of transgenic technology is an obstacle for its develop- } \\
\text { ment }\end{array}$ \\
\hline \multirow[t]{2}{*}{ Informational } & $\begin{array}{l}\text { Inconspicuous role of the mass media in introducing the achievements of transgenic technology has led to backwardness of } \\
\text { this technology }\end{array}$ \\
\hline & Lack of accurate statistical information on transgenic plants has prevented the growth of this area \\
\hline
\end{tabular}

based on the opinions of other panel members. Concepts that have a high agreement in both Tables 2 and 3 and whose rankings do not change, have been approved by all panel members, while the shift in the ranking of some concepts in Table 3 compared to their ranking in Table 2 reflects a change in the perspectives of panel members according to the views of other panel members.

The results indicated that 14 concepts out of 16 ones outlined in opportunities received agreement scores above $80 \%$. In addition, the results showed that the experts of transgenic products agreed most on two concepts including "population growth and nutritional needs of human beings reflect the necessity of producing transgenic plants" (96.7\%) and "the technology of transgenic plants supports sustainable agriculture development goals" (93.3\%). On the other hand, two concepts of "cultivation of transgenic plants can lead to soil protection" and "cultivation of transgenic plants preserves biodiversity" achieved the lowest levels of agreement. 
Analyzing the levels agreement on the concepts related to challenges for the use and production of transgenic products showed that 17 concepts out of 25 concepts received agreement scores above $80 \%$. The concepts "production of transgenic plants in Iran is unnecessary and traditional breeding methods can meet future food needs" and "due to political issues and deficiencies in planning, the production of transgenic plants has faced with some problems" had the highest percent of agreement. That is while the concepts "the use of transgenic plants can create risks for human reproduction and fertility" and "the use of transgenic plants may cause tumors (cancer) and allergies in individuals" obtained the lowest level of agreement in this dimension.

According to the scholars [see 32], achieving full agreement on the concepts is not expected. However, $80 \%$ is set as an acceptable and reasonable agreement level [32]. Therefore, all the concepts that received agreement less than $80 \%$ were removed from the list of challenges and opportunities. Eventually, 14 concepts of opportunities and 17 concepts of challenges reached an acceptable level of agreement. The agreed concepts are highlighted in Table 3.

In order to obtain more objective and understandable results, the concepts of opportunities and challenges which obtained the level of agreement above $80 \%$ were summarized. Therefore, the concepts with similar characteristics represented in the form of more general factors (Table 4). The results of this categorization revealed that the opportunities of transgenic agricultural products include "food security" and "biosafety". The main opportunity of GM agricultural products is their potential promise of future food security, especially for smallscale farmers in developing countries. The arguments of transgenic products' supporters are safe food security, improved food quality, and extended shelf-life as the reasons why they believe in GM products which will benefit not only both consumers and farmers, but also the environment $[16,20]$. Transgenic products may be one of the solutions for hunger in the developing countries and people of these countries must have knowledge about benefits and dangers and the freedom to make their own decisions about whether or not they grow and consume these crops [33]. Moreover, transgenic products can contribute to design new foods with specific health protective properties, but given the relatively poor stateof-the-art with respect to knowledge. So, information on working mechanisms, joint study on epidemiology, nutrition, and food toxicology is first needed in order to select relevant compounds and to demonstrate their beneficial action [17, 34]. Food security and biosafety as the opportunities of transgenic agricultural products have been supported by other researchers including Tscharntke et al. [33], Santeramo [34], and Qaim and Kouser [35].
The challenges can also be configured in the form of "structural-managerial", "educational", “cognitive”, and "informational" challenges. Existence of structural-managerial challenges for development of transgenic products in Iran has been supported by Pezeshki Rad and Naeemi [36], Ghanian et al. [20], Azadi et al. [37], and Azadi et al. [21]. They have argued that there are no clear rules and structures about development of transgenic products. In addition, management positions are occupied by inexpert and unpracticed individuals who do not have sufficient knowledge about agricultural and transgenic products. Regarding educational challenges, it is worth mentioning that education is an important issue in every innovation [37]. Other studies [17, 38] have also emphasized on the importance of this point and stated that transgenic technology needs proper education, because regardless of this component, technology cannot be passed on to individuals (especially farmers). In addition, Akbari and Asadi [39] consider education as the first factor affecting distribution of the market. Taking cognitive and informational challenges into account is also a fact that can be very beneficial for promotion of transgenic products in Iran. It should always be kept in mind that cognitive and informative changes are considered as the first steps for educational and structural-managerial changes [40-43].

\section{Conclusion and recommendations}

The first opportunity to develop transgenic agricultural products in this study was "food security with the dimensions availability, quality, and safety". Since putting emphasize on this opportunity can lead to the results such as meeting nutritional needs of societies, increasing agricultural production, increasing economic profit, eliminating poverty, and promoting healthy and safe food. In a country like Iran, food security will be achieved when everyone at any given time has physical, social, and economic access to adequate, safe, and nutritious food, so that they can meet their food and nutritional needs for healthy and active life. Given that the current agricultural industry of Iran has not had much success in this context and the population of the country has increased rapidly over the years, therefore, policymakers, decision-makers and program-planners must try to use the potentials of transgenic agricultural products in this field. Biosafety is the second opportunity provided by development of genetic engineering and transgenic technologies. Therefore, it may not be logical to prohibit the use and production of transgenic agricultural products in a country like Iran that is faced with many economic and political problems in ensuring food security for its people. Accordingly, appropriate policies and guidelines should be designed for the cautious and useful application of genetic engineering to be guaranteed. 
According to the experts, structural-managerial challenge is the first and most important challenge for development of transgenic plants. This challenge mainly refers to inadequacy of traditional plant breeding practices, political issues and lack of planning, little attention of officials, lack of an enabling environment for private sectors activity, problems in management systems, regulatory and controlling organizations, policymakers' resistance, and gigantic administrative bureaucracy. These results suggest that establishing strong financial, management, monitoring, and controlling systems is a must for institutionalization of transgenic agricultural products. In other words, mismatch of management positions with specialties of managers, lack of competence, and weaknesses in current structures and policies of biotechnology are among the most significant problems in Iran's sovereign body. Therefore, for the better utilization of the potentials of transgenic products and genetic engineering, it is recommended that the top-down structure of biotechnology system be revised. This will pave the way for private sector activities in the field of production and exploitation of transgenic products. Through its customer-oriented and demand-driven service delivery approach, private sector can offer both higher-quality products and can also contribute to solving problems related to monitoring, control, and planning.

Educational problems are another major challenge for transgenic agricultural products. This challenge is consisted of concepts such as "lack of an educational, research, and development system (ERDS) for transgenic products", "lack of educators and knowledgeable specialists in transgenic technology", " non-certification of transgenic products by recognized scientific and research authorities", "lack of consensus among experts on the usage of transgenic products", and "low speed of the process of generating knowledge and technology on transgenic plants". From the implications of this challenge, it can be deduced that there are profound educational gaps in the field of transgenic innovation in Iran. Agricultural Extension is one of the organizations that can contribute to suitable education of agricultural societies in the field of transgenic technologies. Therefore, it is recommended that extension services be used to introduce new technology to manufacturers and to educate them on how to use it. However, before educating individuals, agricultural extension field staff and researchers need to adapt these technologies to the needs of the target group.

Lack of familiarity with methods/goals/results of genetic engineering and lack of awareness of consumers and manufacturers about the features of transgenic technology are considered as cognitive challenge in this research. Information is the fourth challenge which is closely related to cognitive and educational challenges.
In fact, the lack of familiarity with methods, goals, and results of genetic engineering and gene transferring methods is the most important aspect of public concern. Although it is not possible to get full knowledge about genetic engineering and genetic manipulation methods for all those who are the consumer of transgenic products, their awareness and recognition about the goals and positive/negative effects of the use of these products can be increased using specific strategies. For instance, one of the strategies is to focus and invest on mass media that provide some advantages such as high availability, vast coverage, and low-cost. Accordingly, mass media (such as radio and television) can act as the best educational and informational tools for development and application of transgenic plants.

The present study, like any other research, had limitations that need to be considered in future researches by other researchers. First, due to economic constraints in the present study, the samples in snowball sampling method consisted of the experts/specialists of plant breeding and biotechnology. However, it should be kept in mind that experts or specialist are considered as one of the stakeholders in development of the network of transgenic products. Farmers, policymakers, and end-users of transgenic products in the rural and urban communities are other stakeholders that their perspective on the challenges and opportunities of transgenic products can be taken into account. Therefore, future studies are recommended to a multi-group Delphi technique to this end. Second, this study was carried out for analyzing the challenges and opportunities of transgenic products in Iran using Delphi method. In other words, the main aim of Delphi method is consensus building on a specific subject like opportunities and challenges of transgenic agricultural products and developing a primary model for being used in future studies. Present study articulated the challenges and opportunities in some dimensions and indicators (items). Future studies can use this model in quantitative and survey studies in order to validate and increase the generalizability of the results.

Delphi method in general and the present study in particular are considered as "descriptive methodological approach" to identify the initial model of a subject. Therefore, this method does not seek to use inferential analysis methods. In other words, the descriptive model extracted in this study can be analyzed in future research using inferential methods such as different regression models, structural equation modeling, and so on. Such analyses not only assess the validity of the proposed model, but also will deepen the results of present study on challenges and opportunities of transgenic agricultural products. 


\section{Abbreviations}

GM: Genetically modified; ERDS: Educational, Research and Development System.

\section{Acknowledgements}

The authors hereby express their special gratitude to all the experts who completed the study questionnaires with great patience.

\section{Authors' contributions}

All three authors participated in data collection, supervision, analysis, description and drafted the manuscript. All authors read and approved the final manuscript.

\section{Funding}

This paper is part of a M.Sc. thesis submitted at Department of Agricultural Extension and Education, School of Agriculture, Shiraz University, Shiraz, Iran. This study would not have come to fruition without of the technical and financial support of Educational Institution of Shiraz University.

\section{Availability of supporting data}

Not applicable.

\section{Ethical approval and consent to participate}

Prior to starting the work, the study design was fully explained to respondents to obtain consent. No false promise such as remuneration and or per diem, food, and financial aids was given. Information was collected after securing consent from study participant. Data obtained from each study participant were kept confidential, and all peoples who participated in the study were acknowledged. The consent form has been read to me and voluntarily I agree to participate in this study.

\section{Consent for publication}

Not applicable, because there is no data contained within our manuscript from which participants may be identified.

\section{Competing interests}

The authors declare that they have no competing interests.

Received: 17 January 2020 Accepted: 26 May 2020

Published online: 07 August 2020

\section{References}

1. Dayani S, Sabzalian MR. Genetically modified plants as sustainable and economic sources for RUTFs. Genetically engineered foods. New York: Academic Press; 2018. p. 49-84. https://doi.org/10.1016/B978-0-12-81151 9-0.00003-0.

2. Barrows G, Sexton S, Zilberman D. Agricultural biotechnology: the promise and prospects of genetically modified crops. J Econ Perspect. 2014;28(1):99-120. https://doi.org/10.1257/jep.28.1.99.

3. Ahmad N, Mukhtar Z. Genetic manipulations in crops: challenges and opportunities. Genomics. 2017;109(5-6):494-505. https://doi. org/10.1016/j.ygeno.2017.07.007.

4. Ghasemi Tazangane S. Transgenic products, Knowledge, Attitudes and behavioral intentions of agricultural professionals in fars province. Master's thesis. Shiraz University, Shiraz, Iran; 2008.

5. Valizadeh N, Bijani M, Hayati D, Haghighi NF. Social-cognitive conceptualization of Iranian farmers' water conservation behavior. Hydrogeol J. 2019;27(4):1131-42. https://doi.org/10.1007/s10040-018-01915-8.

6. Baltes NJ, Gil-Humanes J, Voytas DF. Genome engineering and agriculture: opportunities and challenges. Progress in molecular biology and translational science, vol. 149. New York: Academic Press; 2017. p. 1-26. https://doi.org/10.1016/bs.pmbts.2017.03.011.

7. FAO. State of food insecurity in the world in brief, Rome. Research Report. Italy; 2018.

8. National Academy of Washington DC. Transgenic plants and global agriculture. Translated by Bahman Yazdi Samadi, Ali Akbar Shah Nayat Bushehri. Tehran: Mehr Publication; 2001.

9. Naeemi A, Pezeshki Rad GH, Ghareyazie B. Examining the problems of development of agricultural biotechnology from the point of view of Tehran's biotechnology experts. Iran J Iran Agric Econ Dev Res. 2011;1:45-56.

10. Aghaee MA, Olkowski SM, Shelomi M, Klittich DS, Kwok R, Maxwell DF, Portilla MA. Waiting on the gene revolution: challenges for adopting GM crops in the developing world. Trends Food Sci Technol. 2015;46(1):132-6. https://doi.org/10.1016/j.tifs.2015.09.001.

11. Shojaee A, Miramadi T, Momeni F, Hosseini Hajiallah H. Challenges for the development of transgenic plants in terms of inequality and policies to deal with it. Iran J Sci Promot Promot Scie. 2016;10:95-105.

12. Bazuin S, Azadi H, Witlox F. Application of GM crops in Sub-Saharan Africa: lessons learned from Green Revolution. Biotechnol Adv. 2011;29(6):90812. https://doi.org/10.1016/j.biotechadv.2011.07.011.

13. Gheyasvand Ghiyasi F, Mirakzadeh A, Shiri N. Factors affecting consumer attitudes toward transgenic food products: qazvin. Iran J Agric Econ Dev Res. 2015;3:427-38.

14. James C. Report on global status of commercialized biotech/GM crops: 2014. ISAAA, Research Report. Philippines.

15. ISAAA. Global status of commercialized biotech/GM crops in 2018: Biotech crops continue to help meet the challenges of increased population and climate change. ISAAA Brief No. 54, International Service for the Acquisition of Agri-Biotech Applications: ISAAA; 2018. Ithaca, New York, http://www.isaaa.org/resources/publications/briefs/54/default.asp. Accessed 5 Sept 2019.

16. Tscharntke T, Clough Y, Wanger TC, Jackson L, Motzke I, Perfecto I, Vandermeer J, Whitbread A. Global food security, biodiversity conservation and the future of agricultural intensification. Biol Cons. 2012;151(1):53-9. https ://doi.org/10.1016/j.biocon.2012.01.068.

17. Azadi H, Ho P. Genetically modified and organic crops in developing countries: a review of options for food security. Biotechnol Adv. 2010;28(1):160-8. https://doi.org/10.1016/j.biotechadv.2009.11.003.

18. Qaim M. Benefits of genetically modified crops for the poor: household income, nutrition, and health. N Biotechnol. 2010;27(5):552-7. https://doi. org/10.1016/j.nbt.2010.07.009.

19. Santeramo FG. On the composite indicators for food security: Decisions matter! Food Rev Int. 2015;31(1):63-73. https://doi.org/10.1080/87559 129.2014.961076.

20. Ghanian M, Ghoochani OM, Dorani M. The gene revolution: is it a solution for solving food insecurity issues. Ann Agric Crop Sci. 2016;1(3):1012.

21. Azadi H, Samiee A, Mahmoudi H, Jouzi Z, Rafiaani Khachak P, De Maeyer P, Witlox F. Genetically modified crops and small-scale farmers: main opportunities and challenges. Crit Rev Biotechnol. 2015;36(3):434-46. https:// doi.org/10.3109/07388551.2014.990413.

22. Ghareyazie B. Biosafety and genetic engineering issues. Iran J Approach. 2002;28:47-85.

23. Khalid S, Yousaf Z, Shahid A. Engineered organisms (plants and animals) In: Holban AM, Grumezescu AM, editors. Genetically engineered foods. London: Academic Press; 2018. p. 49-84.

24. Dutta J. Genetically modified (GM) foods: the food security dilemma. Food safety in the 21st Century. London: Academic Press; 2017. p. 507-14. https://doi.org/10.1016/B978-0-12-801773-9.00042-X.

25. Pino G, Amatulli C, De Angelis M, Peluso AM. The influence of corporate social responsibility on consumers' attitudes and intentions toward genetically modified foods: evidence from Italy. J Clean Prod. 2016;112:2861-9. https://doi.org/10.1016/j.jclepro.2015.10.008.

26. Azmi A, Movahed Mohammadi H, Ebravani H, Behamta MR. Use of transgenic plants from the viewpoint of the faculty members of agricultural research centers and agricultural colleges of selected groups in Tehran and Guilan Provinces, "Weaknesses and Strengths". Iran J Res Dev. 2008;21:11-9.

27. OECD. Safety assessment of transgenic organisms in the environment, Volume 7: OECD Consensus Documents, Harmonisation of regulatory oversight in biotechnology. Paris: OECD Publishing; 2017. https://doi. org/10.1787/9789264279728-en.

28. Pray CE, Nagarajan L, Huang J, Hu R, Ramaswami B. Impact of Bt cotton, the potential future benefits from biotechnology in China and India. In: Carter C, Moschini G, Sheldon I, editors. Genetically modified food and global welfare. Bindley: Emerald group Publishing; 2011. p. 83-114.

29. Ahmadi FA, Nasiriani KH, Abazari P. Delphi technique: a tool in the research. Iran J Med Educ. 2008;8:175-85. 
30. Jamali A, Habibi M, Baqi Yazdel R. Application of Delphi method in the behavioral sciences and medical research: a review of advantages, limitations and methodology. Iran J High Educ Lett. 2014;26:131-54.

31. Alidousti S. Delphi Method: basics, Steps and examples of usage. Iran J Manag Promot Promot. 2006;31:8-23.

32. Hsu Chia-Chien, Brian AS. The Delphi Technique: Making Sense of Consensus. Practical Assessment, Research \& Evaluation Journal, 2007; 21(10): $1-9$.

33. Closter AM, Embree E, Petersen M, Pedersen SH. Organic farming and genetically modified crops in relation to food security. Henning $\mathrm{H} ø g h$ Jensen Publication; 2004.

34. Kuiper HA, Noteborn HPJM, Kok EJ, Kleter GA. Safety aspects of novel foods. Food Res Int. 2002;35:267-71.

35. Qaim M, Kouser S. Genetically modified crops and food security. PLoS ONE. 2013;8(6):1-7.

36. Pezeshki Rad GhR, Naeemi A. Investigating the effective extension educational factors on the use of transgenic plants in the viewpoint of biotechnology experts in research centers of Tehran Province. Iran J Agric Econ Dev Sci Technol Agric. 2011;1:1-9.

37. Haji L, Valizadeh N, Rezaei-Moghaddam K, Hayati D. Analyzing Iranian farmers' behavioral intention towards the acceptance of drip irrigation using Extended Technology Acceptance Model. J Agric Sci Technol 2020; 22(5): (In press)

38. Azadi H, Ghanian M, Ghoochani OM, Rafiaani P, Taning CN, Hajivand RY, Dogot T. Genetically modified crops: towards agricultural growth, agricultural development, or agricultural sustainability? Food Rev Int. 2015;31(3):195-221. https://doi.org/10.1080/87559129.2014.994816.
39. Akbari M, Asadi AA. Comparative Study of Iranian Consumers'Versus Extension Experts' Attitudes towards Agricultural Organic Products (AOP). Agric Biol Sci. 2008;3:551-8.

40. Valizadeh N, Bijani M, Abbasi E, Ganguly S. The role of time perspective in predicting Iranian farmers' participatory-based water conservation attitude and behavior: the role of time perspective in water conservation behavior. J Hum Behav Soc Environ. 2018;28(8):992-1010. https://doi. org/10.1080/10911359.2018.1485602.

41. Bijani M, Ghazani E, Valizadeh N, Haghighi NF. Predicting and Understanding Farmers' Soil Conservation Behavior in Mazandaran Province, Iran. J Agric Sci Technol. 2019;21(7):1705-19. https://doi.org/10.1016/j.iswcr 2017.03.001.

42. Bijani M, Ghazani E, Valizadeh N, Haghighi NF. Pro-environmental analysis of farmers' concerns and behaviors towards soil conservation in central district of Sari County, Iran. Int Soil Water Conserv Res. 2017;5(1):43-9. https://doi.org/10.1016/j.iswcr.2017.03.001.

43. Valizadeh N, Bijani M. Application of Maslow's needs theory to analyze environmental aesthetics attitude of rural people in Miandoab Township. Iran Agric Extens Educ J. 2017;12(2):211-27.

\section{Publisher's Note}

Springer Nature remains neutral with regard to jurisdictional claims in published maps and institutional affiliations.
Ready to submit your research? Choose BMC and benefit from:

- fast, convenient online submission

- thorough peer review by experienced researchers in your field

- rapid publication on acceptance

- support for research data, including large and complex data types

- gold Open Access which fosters wider collaboration and increased citations

- maximum visibility for your research: over $100 \mathrm{M}$ website views per year

At BMC, research is always in progress.

Learn more biomedcentral.com/submissions 